\title{
EFFECT OF PROPOLIS ORAL INTAKE ON PHYSIOLOGICAL CONDITION OF YOUNG WORKER HONEY BEES, APIS MELLIFERA L.
}

\author{
Natalia Damiani ${ }^{1,2 *}$ \\ Martín P. Porrini ${ }^{1,2}$ \\ Juan P. Lancia 2,3 \\ Estefanía Álvarez ${ }^{1}$ \\ Paula M. Garrido ${ }^{1,2}$ \\ Enzo Domínguez ${ }^{1}$ \\ Liesel B. Gende1,2 \\ Martín J. Eguaras ${ }^{1,2}$ \\ ${ }^{1}$ Centro de Investigación en Abejas Sociales. Facultad de Ciencias Exactas y \\ Naturales. Universidad Nacional de Mar del Plata. Funes 3350 (7600) Mar del Plata. \\ Buenos Aires. Argentina. \\ ${ }^{2}$ Consejo Nacional de Investigaciones Científicas y Técnicas (CONICET), Argentina \\ ${ }^{3}$ Laboratorio de Invertebrados, Instituto de Investigaciones Marinas y Costeras \\ (IIMyC), Departamento de Biología, Facultad de Ciencias Exactas y Naturales, \\ Universidad Nacional de Mar del Plata. Funes 3250 Casilla de Correo 1260, Mar del \\ Plata, Argentina \\ *corresponding author: nataliadamiani@gmail.com \\ Received: 7 April 2016; accepted: 6 November 2017
}

Abstract

Honey bees collect resin from various plant species and transform it into propolis that is incorporated into the nest. The role of resins in the bee health field is poorly understood. The aim was to evaluate the effects of forced consumption of propolis on the physiological condition and short-term survival of Apis mellifera worker bees. It was tested if the number of circulating hemocytes in hemolymph, the abdominal fat bodies and the hypopharyngeal glands development were affected by the feeding with propolis extracts in laboratory conditions during the warm and the cold seasons. Propolis added to sugar candy was consumed by workers for fourteen days without affecting the bee survival. The number of circulating hemocytes in hemolymph remained constant despite the differential diet during the experiment. However, the development of fat bodies and hypopharyngeal glands was altered by propolis ingestion. The abdominal fat body development in winter bees diminished after fourteen days of propolis consumption, while it increased in summer bees. The hypopharyngeal gland development decreased for the assayed period in workers from both seasons. Our results encourage us to continue exploring this research field and learn how long-term forced ingestion of a plant-derived compound, a non-nutritive substance, can modify physiological bee parameters. A broader understanding of the multiple roles of propolis in the health of the honey bee colonies could be obtained by studying the ways in which it is processed and metabolized and the effect that generates in another physiological responses.

Keywords: circulating hemocytes, fat body, hypopharyngeal glands, propolis intake, worker honeybees

\section{INTRODUCTION}

Social insects have developed behaviors in which individuals cooperate to avoid pathogen transmission within the colony (Wilson-Rich, Dres, \& Starks, 2008). When hundreds of individuals interact, the response at a colony level has analogous properties to the complex humoral and cellular immune systems (Cremer \& Sixt, 2009). In honey bees this process has been termed "social immunity" and is known to reduce the pathogen loads and the stress at group level (Wilson-Rich et al., 2009). One of these social mechanisms is the collection and 
in-hive use of resins, plant complex secretions with diverse biological properties.

Honey bees transform resins from various plant species in propolis, an antiseptic substance that is incorporated into the nest architecture for reducing the bacterial load and the overall investment in individual immune functioning, positively affecting the colony fitness (Simone, Evans, \& Spivak, 2009; Simone-Finstrom \& Spivak, 2010). The plant resins collected to manufacture propolis contain many of the same polyphenols found in pollen and nectar, but in much higher quantities (Burdock, 1998; Bankova, De Castro, \& Marcucci, 2000). However, while bees consume bee bread and honey, they do not seem to actively eat propolis (König, 1988). In animal groups where self-medication with plants occurs, individuals modify their diets (pharmacophagy) in response to infections. In the case of bees, individuals use the resin within the nest (pharmacophory) but apparently without ingesting it (Erler \& Moritz, 2016).

Most available literature has referred to the chemical composition and biological activity of plant-derived propolis and resin mixtures and focused mainly on the human health field (Bogdanov, 2015). Few works have studied the role played by these resins in the control and resistance to the diseases in honey bee colonies. Propolis has proven to be active against the main bee threats such as the bacterium Paenibacillus larvae (Antúnez et al., 2008; Bastos et al., 2008; Mihai et al., 2012), the fungus Ascosphaera apis (Wilson et al., 2015), and the mite Varroa destructor (Damiani et al., 2010). In colonies of Apis mellifera L. (Hymenoptera: Apidae), the propolis added into the nest environment modified the expression of immunerelated genes in the exposed worker bees (Simone, Evans, \& Spivak, 2009). However, possible effects on the physiological or immune responses from bees after a prolonged intake of propolis have not been evaluated. Only Johnson et al. (2012) was able to show that the oral administration caused overexpression of detoxification-related genes probably because flavonoids from propolis, honey and pollen represent a challenge toxic to bees (Mao,
Schuler, \& Berenbaum, 2015).

The physiological condition of worker honeybees varies according to their lifespan temporal differentiation and the seasonality (Amdam \& Omholt, 2002; Amdam \& Seehuu, 2006). The development degree of the abdominal fat bodies and the hypopharyngeal glands, and the number of circulating hemocytes in hemolymph would offer a general idea of the physiological status of the bee. The fat bodies are vitally important for bees by providing energy, antimicrobial peptides and lysozyme (Gillespie, Kanost, \& Trenczek, 1997). Furthermore, large amounts of relevant proteins, such as storage proteins used as an amino acid reservoir, lipophorins for the lipid transport or vitellogenin are also secreted by the fat body (Keeley, 1985). Their size variation has been related to the overall condition of an insect. The amount of proteins in the fat bodies of a worker bee peaks at twelve days in summer, while it may increase far beyond this level in late autumn and decreases during winter (Fluri \& Bogdanov, 1987).

In nurse bees, the hypopharyngeal glands synthesize royal jelly that feeds the larvae and also produce substances with antiseptic and antimicrobial properties which are added to honey (Hrassnigg \& Crailsheim, 1998). In summer bees, gland development and protein content increase during the first five-ten days of adult life but tend to decline during the winter (revised in Amdam \& Omholt, 2002).

In hemolymph, the hemocytes are responsible for the phagocytosis, nodulation and encapsulation of pathogen agents. They also produce antibacterial peptides and contain crucial enzymes for the wound healing response (Lavine \& Strand, 2002). The circulating hemocytes are easily accessible for the evaluation of an insect's homeostasis of. This then allows the estimation of the influence of such various external factors as nutritional deficiencies (Szymaś \& Jędruszuk, 2003) or the ability of an individual to face an immune challenge (Marmaras \& Lampropoulou, 2009).

Nurse bees have well developed hypopharyngeal glands, hypertrophied abdominal fat bodies, and abundant circulating hemocytes. In forager 
bees over 21 days old, the hypopharyngeal glands and abdominal fat bodies are atrophied and have very few circulating haemocytes (de Moraes \& Bowen, 2000; Amdam \& Omholt, 2002). Diutinus or winter bees develop in nonfavourable periods without brood care opportunities (Amdam \& Page, 2005). They show hypertrophied hypopharyngeal glands, hypertrophied fat bodies and a large number of hemolymphatic cells, regardless of the task performed within the colony.

The aim of this work was to evaluate how the forced consumption of propolis affects the short-term survival of $A$. mellifera workers and the physiological condition by testing the circulating hemocyte number in hemolymph, abdominal fat bodies and hypopharyngeal gland development laboratory conditions during summer and winter.

\section{MATERIAL AND METHODS}

\section{Experimental animals}

Healthy $A$. mellifera colonies were placed in an experimental apiary of the National University of Mar del Plata, Argentina (38 $10^{\prime} 06^{\prime \prime}$ S; $57^{\circ} 38^{\prime} 10^{\prime \prime}$ W). Ten Langstroth hives with young sister queens provided by a regional beekeeping house were maintained with a homogeneous brood and bee population. For the experiments, capped brood combs were removed from three colonies and maintained in lab conditions at 32 $\pm 1{ }^{\circ} \mathrm{C}$ and $60 \% \mathrm{RH}$ until bees emerged. Due to seasonality influence, the physiological state of workers, bioassays were developed during two different periods in 2012: August (cold season) and December (warm season).

\section{Propolis extracts}

A raw propolis sample was collected from an

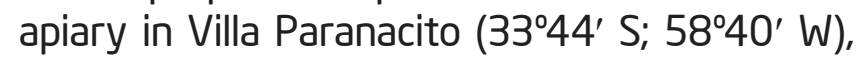
Entre Ríos, Argentina. The sample was weighed, frozen, ground and stored at $4^{\circ} \mathrm{C}$ until use. For the experiment, a soft propolis extract was prepared according to Damiani et al. (2010). A suspension was elaborated from the raw propolis and ethanol $70 \%$ at 1:9 (w/v) ratio, extracted at $60^{\circ} \mathrm{C}$ for $2 \mathrm{~h}$, filtered and then evaporated at $40^{\circ} \mathrm{C}$ to obtain a soft extract free of ethanol.

\section{Experimental procedure}

Newly emerged bees were randomly confined to experimental wooden cages with enough ventilation $\left(11 \times 9 \times 6 \mathrm{~cm}^{3}\right)$. Three replicates of about 70 individuals per group were used. Separate feeders with water, fresh bee bread, and one of two sugar diets were ad libitum supplied to one-day-old bees. The control group received 'sugar candy' (composed of three parts glucose and seven parts powdered sugar) and the treatment group received sugar candy with added $10 \%(\mathrm{w} / \mathrm{w})$ propolis (composed of one part soft propolis extract, two parts glucose, and seven parts powdered sugar). The propolis concentration used for the latter diet was estimated according previous data about bee toxicity. Their water was replaced, food status checked and consumption registered each day. Diets were replaced every three days to prevent drying and microbial growth. Dead bees were removed and counted during each cage inspection. The bees were fed for a total of fourteen days. Bee bread and candy consumption rates were determined and corrected for survival by estimating the mean intake per alive bee (calculated as milligrams of food/bee/day). For the evaluation of the different parameters, the bees were sampled on the 7th and 14th day (see details below). An average of $13.17 \pm 4.67$ bees per replicate was sacrificed. Each sampled bee was used to test the following variables:

Hypopharyngeal gland development: The acini diameter is an indicator of the gland's activity and reflects the amount of proteins produced (Knecht \& Kaatz, 1990). A simple method relates positively the acini size of the hypopharyngeal glands (and, therefore, their degree of hypertrophy) with the head fresh weight (Hrassnigg \& Crailsheim, 1998; Babendreier et al., 2005; Deseyn \& Billen, 2005), and it was also verified with a subsample of our study cases (unpublished data). Bee heads were removed and weighed to estimate the hypopharyngeal gland development. The head width was measured according to McMullan \& Brown (2006). For that, sampled bees were dissected and preserved in $70 \%(w / v)$ ethanol. Heads were individually removed, mounted on 
a glass slide and fixed with adhesive tape. Each mounted slide was placed next to a precision caliber, as a size reference, and then photographed (KODAK Camera; resolution: 12mpx). The digitalized pictures were analyzed with Image J software.

Abdominal fat body development: The development degree of fat bodies from bee abdomen was estimated using a modified technique of Wilson-Rich, Dres, \& Starks (2008). Abdomens were dissected and placed to dry into individual containers lined with foil. The drying to constant weight was carried out at $40{ }^{\circ} \mathrm{C}$ for five-six days. Then, each abdomen was transfer and kept for two days in ethyl ether, and afterwards was re-dried and weighed again (Mettler Toledo AL104 Scale; accurate to 0.0001 g). The relative mass of fat bodies was estimated as the percentage change in abdominal weight after the washing with ethyl ether.

Circulating hemocytes: To determine the total hemocyte counting (THC), hemolymph from each immobilized bee was extracted through puncturing of the dorsal aorta with a needle and collecting the resulting drop with a micropipette. Two $\mu \mathrm{L}$ of hemolymph were diluted in ten $\mu \mathrm{L}$ of anticoagulant buffer (ABIl: $0.098 \mathrm{M} \mathrm{NaOH}$, $0.146 \mathrm{M} \mathrm{NaCl}, 0.017 \mathrm{M}$ EDTA, $0.041 \mathrm{M}$ citric acid, buffer pH 4.5; Mead, Ratcliffe, \& Renwrantz, 1986) and transferred to an improved Neubauer hemocytometer (Amaral et al., 2010). Cells were counted ten min after. The number of circulating hemocytes per $\mathrm{mm}^{3}$ of hemolymph was calculated with the formula by Jones (1962).

\section{Statistical analysis}

The mean amounts of different consumed diets during the experiment were compared using a one-way ANOVA, with the treatments as factors and colonies as replicates. The dietary effects on each individual physiological parameter (circulating hemocytes, fat body or hypopharyngeal gland development) at seven and fourteen days after treatment were determined with one-way ANOVA followed by Tukey post hoc tests $(\alpha=0.05)$. The Kruskal-Wallis test was used for multiple comparisons of bee mortality after treatments.

The development of hypopharyngeal glands was estimated through the weighing of the head. To rule out that variation in head weight was due to variation in bee head size, the Pearson's correlation coefficient between the weight and the width of the head was calculated.

\section{RESULTS}

\section{Diet consumption and bee survival}

During fourteen days of treatment, the mean consumption of the sugar diets was $6.17 \pm 1.19$ and $4.49 \pm 1.11 \mathrm{mg} / \mathrm{bee} /$ day for control and propolis groups, respectively. These values did not significantly differ between groups ( $F[3$, $8]=2.63, p=0.122$ ). The bee bread consumption showed similar results: $4.35 \pm 1.62$ and $3.62 \pm 2.12 \mathrm{mg} / \mathrm{bee} /$ day for control and treated bee groups, respectively $(F[3,8]=0.26, p=0.851)$. The bee mortality after fourteen days of differential feed was $24.66 \pm 2.04 \%$ for control and $16.27 \pm 10.78 \%$ for propolis group of winter bees, and $19.62 \pm 2.38$ and $31.20 \pm 2.79 \%$ for both treatment groups respectively in summer bees. These values were not significantly different from each other $(H[3, N=12]=7.63, p=0.054)$.

\section{Effects on the physiological condition}

Groups of bees from each season of the year were compared independently. After fourteen days of eating propolis, treated bees showed a lower head weight than the control group (Fig. $1: A$ and $B ; F[3,88]=10.53, p=0.00001$ for cold season group and $F[3,140]=6.91, p=0.00023$ for warm season group). In the warm season group, a slight decrease in the head weight was also observed after seven days of propolis consumption. The correlation analysis showed that the head weight variation was independent of the head width for all cases. The Pearson's correlation coefficient was 0.0238 for the cold season bees and 0.0022 for the warm season ones.

The relative mass of abdominal fat bodies from the control groups increased throughout the assayed periods, and fourteen day-old bees showed more developed fat bodies than seven day-old bees (Fig. 1: C and D; F[3,76]=7.22, $p=0.00025$ for the cold season group and $F[3,104]=12.84, p=0.000001$ for the warm season group). However, the response of bees 

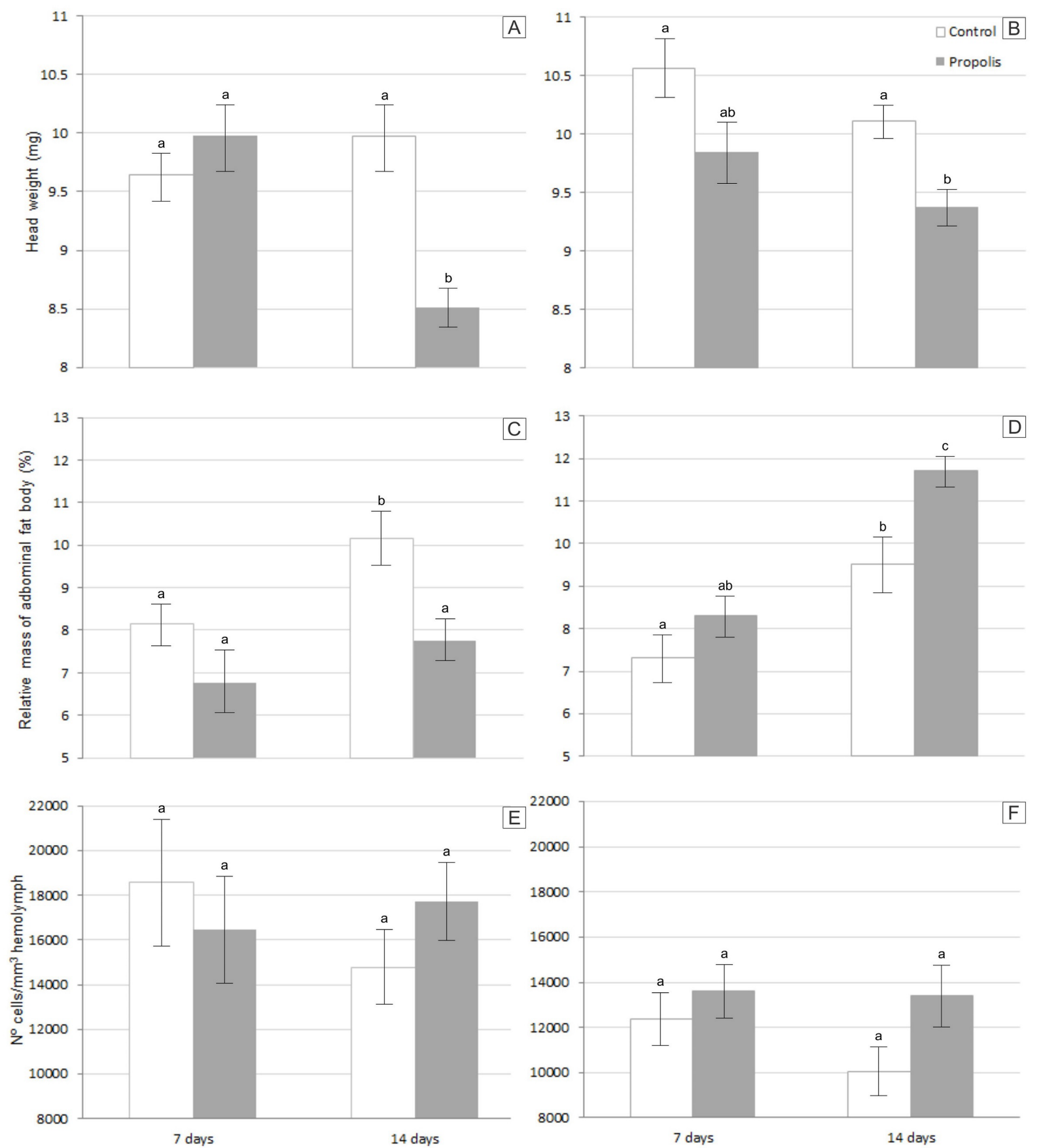

Fig. 1. Average head weight ( $A$ and $B$ ), abdominal fat bodies ( $C$ and $D$ ) and number of circulating hemocytes in hemolymph ( $E$ and $F$ ) in worker bees maintained during forced sugar (Control) and sugar+propolis (Propolis) consumption for fourteen days in the cold season (to the left: $A, C$ and $E$ ) and warm season (to the right: $B, D$ and $F$ ). Letters compare variations among treatments in each sampling season independently. Means with at least one letter in common are not significantly different ( $p>0.05)$.

to propolis intake differed according to the period of the year studied. In bees from the cold season, the fat body mass was reduced after fourteen days of this differentiated diet $(p=0.0031)$, whereas it significantly increased in the warm season bees $(p=0.0085)$. The number of circulating hemocytes in hemolymph did not show a variation to the diets in any group (Fig. 1: $E$ and $F ; F[3,67]=0.64, p=0.591$ for cold season group and $F[3,77]=1.77, p=0.159$ for warm season group). 


\section{DISCUSSION}

Propolis contains more than 300 different compounds including phenolics, fatty acids, terpenoids, carbohydrates, amino acids and vitamins (Bankova, De Castro, \& Marcucci, 2000), but flavonoids are the ones that attract the most scientific research interest (Marcucci, 1995). Many of these phytochemicals are also found in honey and bee bread, which bees produce for consumption, but supposedly not propolis (Simone-Finstrom \& Spivak, 2010).

To avoid the possible influence of the colony genetic origin on the physiological condition of bees, in the present work, different cohorts of newly emerged bees were forced to eat propolis for fourteen days, the propolis extract was added to sugar candy to make it more palatable. Although it seemed to be less palatable than control candy, it was accepted and avidly consumed by bees and did not affect the bee bread consumption. Ebert et al. (2007) stated that some phytochemicals are not toxic for bees when they are orally administered for short periods of time. In the same way, propolis in our short-term consumption assays did not affect the survival of confined worker bees. Johnson et al. (2012) demonstrated that the induction of detoxification enzymes through consuming flavonoids in bee products had improved bee survival. The propolis sample tested here had a phenolic content of $241.1 \mathrm{mg} / \mathrm{g}$ extract (Unpublished data), and due to this high concentration, an extended consumption assay will possibly be necessary to obtain cues of enhanced survival in bees fed propolis.

Some botanical extracts have been shown to affect the cellular immune response by modifying the number of hemocytes, the nodulation and the phagocytosis of pathogen fungal spores in hemolymph of the treated insects (revised in James \& Xu, 2012). Here, the number of circulating hemocytes in hemolymph was similar between the different treatment groups during the exposure time. Therefore, neither the intake of propolis affected the cellular immune response nor, as we infer, that of phytochemicals included in propolis affected the prolif- eration in the hematopoietic tissues or the cell division in the circulating hemocyte population of worker bees. However, its ingestion altered the development of fat body and hypopharyngeal glands, two important tissues related to protein reserve in workers.

There is little data showing how the fat body size is correlated with the immune response (Wilson-Rich, Dres, \& Starks, 2008), but this tissue has been suggested to be size-reduced in worker bees parasitized by Varroa destructor and Nosema sp., making them more susceptible to pesticides (Drescher \& Schneider, 1987). In the present work, the abdominal fat body of bees that emerged during the cold season diminished after fourteen days of continuous propolis intake. Thus, the propolis added to the diet of winter bees appears to have the same effects produced by these parasites (Drescher \& Schneider, 1987).

Furthermore, vitellogenin, one of the major storage proteins synthetized in fat body, increases its titers in this tissue in late autumn (Fluri et al., 1982) because of reduced broodrearing (Amdam et al., 2009), so propolis consumption could have affected this synthesis. For that reason, further experiments related to vitellogenin expression under dietary regime of propolis are necessary. On the contrary, in summer bees the consumption of this supplement promoted the fat body development of workers, which is in agreement with the results obtained by Amdam \& Omholt (2002) who had established that in the warm season fat bodies from twelve days old worker bees had the maximum amount of proteins. In this case, the propolis intake could favor fat body development enhancing the vitellogenin synthesis and hence improve the oxidative stress resistance and the individual humoral defense of workers. Since there is a high availability of nectar, pollen and resins during the summer season, worker bees naturally increase their foraging rates facilitating the incorporation of phenolic compounds to the nest or diet. It is reasonable that seasonality has a significant influence on the physiological activity of the fat bodies. 
During the breeding season, hypopharyngeal gland development and its protein content are expected to be at the maximum level (Amdam \& Omholt, 2002). Nevertheless, in our summer and winter assays the gland size decreased after bees were fed propolis for fourteen days. The phenolic compounds of propolis extract may harm the development and functioning of the hyphopharyngeal glands. Previously, it had been shown that the consumption of some substances like pesticides (Gupta \& Chandel, 1995) or transgenic plants (Babendreier et al., 2005) negatively influenced the development of these glands in bees. Furthermore, Maurizio (1954) suggested that nurses with smaller hypopharyngeal glands would raise fewer offspring and, consequently, reduce honey bee colony performance (Babendreier et al., 2005), although this effect might be compensated by a larger number of bees taking care of the larvae to support the stability of the colony. Thus, in natural conditions a diet supplement with propolis would fail to stimulate well enough the development of the glands in young worker bees and could lead to unsuitable feeding of the brood. For that reason, in further works it will very interesting to study the energetic costs that generates this supplement on colonies.

In research on honey bee health, the role of phytochemicals is poorly understood. A previous study had reported that the oral intake of some isolated compounds found in honey, pollen and propolis strengthen the immune response in honey bees by up-regulating detoxification and immunity genes in the larvae and adult bees (Mao, Schuler, \& Berenbaum, 2013, 2015). We demonstrate that, although fourteen days of propolis consumption did not affect bee survival, it produced sublethal effects by modifying tissues involved in bee metabolism and defense. The diet with propolis affected the protein dynamics in the fat bodies, decreasing it in winter and enhancing it in summer, and also depleted the hypopharyngeal glands. However, the quantity of circulating cells in hemolymph was not modified. We infer that secondary metabolites from propolis affect the humoral but not the cellular immune response of workers in laboratory conditions.
Our research provides the first approach showing how the forced feeding of secondary plant metabolites, as non-nutritive substances extracted from propolis, could modify the physiological condition when added to the worker bee diet for a short period of time. The direct effects of long-term propolis intake on antioxidant and immune-genes of bees should be established in laboratory studies and related to more realistic field conditions. A broader understanding of the multiple roles of propolis in the health of honey bee colonies could be obtained by studying the ways in which it is processed and metabolized and the effect that it generates in other physiological responses.

\section{ACKNOWLEDGEMENTS}

We would like to thank to the beekeepers that contributed the propolis samples and the media involved in the called diffusion, Javier Folgar, Federico Petrera and their team. Special thanks to Lic. P. Giménez Martínez for his indications in morphometric estimations and $\mathrm{K}$. Coonrod for grammar revisions. This study was support by PICT Project No 594/12 to ME (ANPCYT), PICT Project $N^{\circ} 1625 / 11$ to LG (ANPCYT), and Exa Project N ${ }^{0} 664 / 14$ to ND (UNMDP), Argentina.

\section{REFERENCES}

Amaral, l., Moreira Neto, J., Pereira, G., Franco, M., Beletti, M., Kerr, W., Bonetti, A., Ueira-Vieira, C. (2010). Circulating hemocytes from larvae of Melipona scutellaris (Hymenoptera, Apidae, Meliponini): cell types and their role in phagocytosis. Micron, 47(2), 123-129. DOl: 10.1016/.j.micron.2009.10.003

Amdam, G., \& Omholt, S. (2002). The regulatory anatomy of honeybee lifespan. Journal of Theoretical Biology, 216, 209-228. DOl: 10.1006/jtbi.2002.2545

Andam, G., \& Page, R. (2005). Intergenerational transfers may have decoupled physiological and chronological age in a eusocial insect. Ageing Research Reviews, 4(3), 398-408. D0l: 10.1016/j. arг.2005.03.007

Amdam, G., \& Seehuu, S. (2006). Order, disorder, 
death: Lessons from a superorganism. Advances in Cancer Research, 95, 31-60. DOl: 10.1016/S0065230X(06)95002-7

Amdam, G., Rueppell, O., Fondrk, M., Page, R., Nelson, C. (2009). The nurse's load: Early-life exposure to brood-rearing affects behavior and lifespan in honey bees (Apis mellifera). Experimental Gerontology, 44,467-471. DOl: 10.1016/j.exger.2009.02.013

Antúnez, K., Harriet, J., Gende, L., Maggi, M., Eguaras, M., Zunino, P. (2008). Efficacy of natural propolis extract in the control of American Foulbrood. Veterinary Microbiology, 137, 324-331. DOl: 10.1016/j. vetmic.2008.04.011

Babendreier, D., Kalberer, N., Romeis, J., Fluri, P., Mulligan, E., Bigler, F. (2005). Influence of Bt-transgenic pollen, Bt-toxin and protease inhibitor (SBTI) ingestion on development of the hypopharyngeal glands in honeybees. Apidologie, 6(4), 585-594. D0l: 10.1051/apido:2005049

Bankova, V., De Castro, S., \& Marcucci, M. (2000). Propolis: recent advances in chemistry and plant origin. Apidologie, 37, 3-15. DOl: 10.1051/apido:2000102

Bastos, E., Simone, M., Macedo, D., Soares, A., Spivak, M. (2008). In vitro study of the antimicrobial activity of Brazilian propolis against Paenibacillus larvae. Journal of Invertebrate Pathology, 97,273-281. D0l: 10.1016/j.jp.2007.10.007

Bogdanov, S. (2015). Propolis: Composition, Health, Medicine: A Review. Bee Product Science, 1-40.

Burdock, G. (1998). Review of the biological properties and toxicity of bee propolis (Propolis). Food and Chemical Toxicology, 36(4), 347-363. D0l: 10.1016/ S0278-6915(97)00145-2

Cremer, S., \& Sixt, M. (2009). Analogies in the evolution of individual and social immunity. Philosophical Transactions of the Royal Society B, 364, 129-142. DOl: 10.1098/rstb.2008.0166

Damiani, N., Fernández, N., Maldonado, L., Álvarez, A., Eguaras, M., Marcangeli, J. (2010). Bioactivity of prop- olis from different geographical origins on Varroa destructor (Acari: Varroidae). Parasitology Research, 1071), 31-37. DOl: 10.1007/s00436-010-1829-7

de Moraes, R., \& Bowen, I. (2000). Modes of cell death in the hypopharyngeal gland of the honey bee (Apis mellifera L). Cell Biology International, 24(10), 737743. DOl: 10.1006/cbir.2000.0534

Deseyn, J., \& Billen, J. (2005). Age-dependent morphology and ultrastructure of the hypopharyngeal gland of Apis mellifera workers (Hymenoptera, Apidae). Apidologie 36(1), 49-57. D0l: 10.1051/apido:2004068

Drescher, W., \& Schneider, P. (1987). The effect of the Varroa mite upon the fat body of worker bees and their tolerance of pesticides. In Africanized honey bees and bee mites. (pp. 452-456).England: Ellis Horwood Itd. Chichester.

Ebert, T., Kevan, P., Bishop, B., Kevan, S., Downer, R. (2007). Oral toxicity of essential oils and organic acids fed to honey bees (Apis mellifera). Journal of Apicultural Research and Bee World, 46(4), 220-224. DOl: 10.3896/IBRA.1.46.4.02

Erler, S., \& Moritz, R. (2016). Pharmacophagy and pharmacophory: mechanisms of self-medication and disease prevention in the honeybee colony (Apis mellifera). Apidologie, 473), 389-411. DOl: 10.1007/ s13592-015-0400-z

Fluri, P., \& Bogdanov, S. (1987). Age dependence of fat body protein in summer and winter bees (Apis mellifera). In Chemistry and biology of social insects. (pp. 170-171). Munchen: Verlag J. Peperny.

Fluri,P.,Lüscher, M., Wille, H., \& Gerig, L. (1982). Changes in weight of the pharyngeal gland and haemolymph titres of juvenile hormone and vitellogenin in worker honeybees. Journal of Insect Physiology, 28(1), 6168. DOl: 10.1016/0022-1910(82)90023-3

Gillespie, J., Kanost, M., \& Trenczek, T. (1997). Biological mediators of insect immunity. Annual Review of Entomology, 42, 611-43. DOl: 10.1146/annurev. ento.42.1.611 
Gupta, P., \& Chandel, R. (1995). Effects of Diflubenzuron and Penfluron on workers of Apis cerana-indica F. and Apis mellifera L. Apidologie, 26, 3-10. DOl: 10.1051/apido:19950101

Hrassnigg, N., \& Crailsheim, K. (1998). Adaptation of hypopharyngeal gland development to the brood status of honeybee (Apis mellifera L.) colonies. Journal of Insect Physiology, 44(10), 929-939. DOl: 10.1016/S0022-1910(98)00058-4

James, R., \& Xu, J. (2012). Mechanisms by which pesticides affect insect immunity. Journal of Invertebrate Pathology, 109(2), 175-82. D0l: 10.1016/j. jip.2011.12.005

Johnson, R., Mao, W., Pollock, H., Niu, G., Schuler, M., Berenbaum, M. (2012). Ecologically appropriate xenobiotics induce cytochrome P450s in Apis mellifera. PLoS One, 12), e31051. DOl: 10.1371/journal. pone.0031051

Jones, J. (1962). Current concepts concerning insect hemocytes. Integrative and Comparative Biology, 2(2), 209-246. DOl: 10.1093/icb/2.2.209

Keeley, L. (1985). Biochemistry and physiology of the insect fat body. In Comprehensive insect physiology, biochemistry and pharmacology. (pp. 211-228). New York: Pergamon.

Knecht, D., \& Kaatz, H. (1990). Patterns of larval food production by hypopharyngeal glands in adult worker honey bees. Apidologie, 27, 457-467. DOl: 10.1051/apido:19900507

König, B. (1988). The honeybee as pharmacophorus insect. Entomologia Generalis, 14(2), 145-148. DOl: 10.1127/entom.gen/14/1988/145

Lavine M., \& Strand, M. (2002). Insect hemocytes and their role in immunity. Insect Biochemistry and Molecular Biology, 32(10), 1295-1309. DOl: 10.1016/ s0965-1748(02)00092-9

Mao, W., Schuler, M., \& Berenbaum, M. (2013). Honey constituents up-regulate detoxification and immu- nity genes in the western honey bee Apis mellifera. In Proceedings of the National Academy of Sciences of the United States of America (pp. 8842-8846). USA.

Mao, W., Schuler, M., \& Berenbaum, M. (2015). A dietary phytochemical alters caste-associated gene expression in honey bees. Science Advances, 7(7), el500795. DOl: 10.1126/sciadv.1500795

Marcucci, M. (1995). Propolis: chemical composition, biological properties and therapeutic activity. Apidologie, 26(2), 83-99. DOl: 10.1051/apido:19950202

Marmaras, V., \& Lampropoulou, M. (2009). Regulators and signalling in insect haemocyte immunity. Cell Signal, 27(2), 186-195. DOl: 10.1016/j.cellsig.2008.08.014

Maurizio, V. (1954). Pollenernährung und Lebensvorgänge bei der Honigbiene (Apis mellifica L.). Landwirtschaftliches Jahrbuch der Schweiz, 68(2), 115-182.

McMullan, J., \& Brown, M. (2006). The influence of small-cell brood combs on the morphometry of honeybees (Apis mellifera). Apidologie, 376), 665-672. DOl: 10.1051/apido:2006041

Mead, G., Ratcliffe, N., \& Renwrantz, L. (1986). The separation of insect haemocyte types on Percoll gradients; methodology and problems. Journal of Insect Physiology, 32(2), 167-177. DOl: 10.1016/00221910(86)90137-X

Mihai, C., Mărghitaș, L., Dezmirean, D., Chirilă, F., Moritz, R., Schlüns, H. (2012). Interactions among flavonoids of propolis affect antibacterial activity against the honeybee pathogen Paenibacillus larvae. Journal of Invertebrate Pathology, 17011), 68-72. DOI: 10.1016/j. jip.2012.02.009

Simone, M., Evans, J., \& Spivak M. (2009). Resin collection and social immunity in honey bees. EvoIution, 63(11), 3016-3022. DOl: 10.1111/j.15585646.2009.00772.x

Simone-Finstrom, M., \& Spivak, M. (2010). Propolis 


\section{_ DAMIAMI ET HIL___ Propolis feeding effects on honey bee physiology}

and bee health: the natural history and significance of resin use by honey bees. Apidologie, 47(3), 295311. DOl: 10.1051/apido/2010016

Szymaś, B., \& Jędruszuk, A. (2003). The influence of different diets on haemocytes of adult worker honey bees, Apis mellifera. Apidologie, 34(2), 97-102. DOl: 10.1051/apido:2003012

Wilson, M., Brinkman, D., Spivak, M., Gardner, G., Cohen, J. (2015). Regional variation in composition and antimicrobial activity of US propolis against Paenibacillus larvae and Ascosphaera apis. Journal of Invertebrate Pathology, 124, 44-50. D0l: 10.1016/j. jip.2014.10.005

Wilson-Rich, N., Dres, S., \& Starks, P. (2008). The ontogeny of immunity: Development of innate immune strength in the honey bee (Apis mellifera). Journal of Insect Physiology, 54(10-11), 1392-1399. DOl: 10.1016/j.jinsphys.2008.07.016

Wilson-Rich, N., Spivak, M., Fefferman, N., \& Starks, P. (2009). Genetic, individual, and group facilitation of disease resistance in insect societies. Annual Review of Entomology, 54, 405-423. DOl: 10.1146/annurev.ento.53.103106.093301 